\title{
Overview of Amphibian Sexual Dimorphism, with Description of New Secondary Sexual Dimorphic Character in Rhacophorid
}

\section{Frogs}

\author{
Bagaturov $\mathrm{MF}^{1 *}$ and Bagaturova $\mathrm{AA}^{2}$ \\ 1Zoological Institute of the Russian Academy of Sciences, St. Petersburg, Russia \\ ${ }^{2}$ State Budgetary Institution of Additional Education Children's Home of Creativity \\ "Prebrazhenskiy, St. Petersburg, Russia
}

\section{Research Article \\ Volume 1 Issue 1}

Received Date: March 02, 2018

Published Date: March 27, 2018

DOI: $10.23880 /$ izab-16000105

*Corresponding author: Mikhail F. Bagaturov, Zoological Institute of the Russian Academy of Sciences, St. Petersburg, Russia, Tel: +7 (911) 177-65-44; Email: bbigmojo@mail.ru

\section{Abstract}

In this article, brief notes on sexual dimorphism in anuran amphibians are adduced. A beak-like projection in adult males of larger species of Asiatic rhacophorid frogs (Anura: Rhacophoridae) was found to develop during the breeding period of species of larger sizes, and is herein described, illustrated and discussed.

Keywords: Beak-like projection; Rhacophoridae; Sexual dimorphism; Polypedates; Rhacophorus

\section{Introduction}

There are a number of characteristics distinguishing the male and female anuran amphibians (Amphibia: Anura) from each other. This is called "sexual dimorphism." For anuran amphibians, these are more noticeable especially during the breeding (reproduction) period. It was found that the manifestation of a sexual dimorphism in amphibians is lead by fecundity and sexual selection, ecology, and behavioural influences $[1,2]$.

Among those are sexual dimorphisms in:

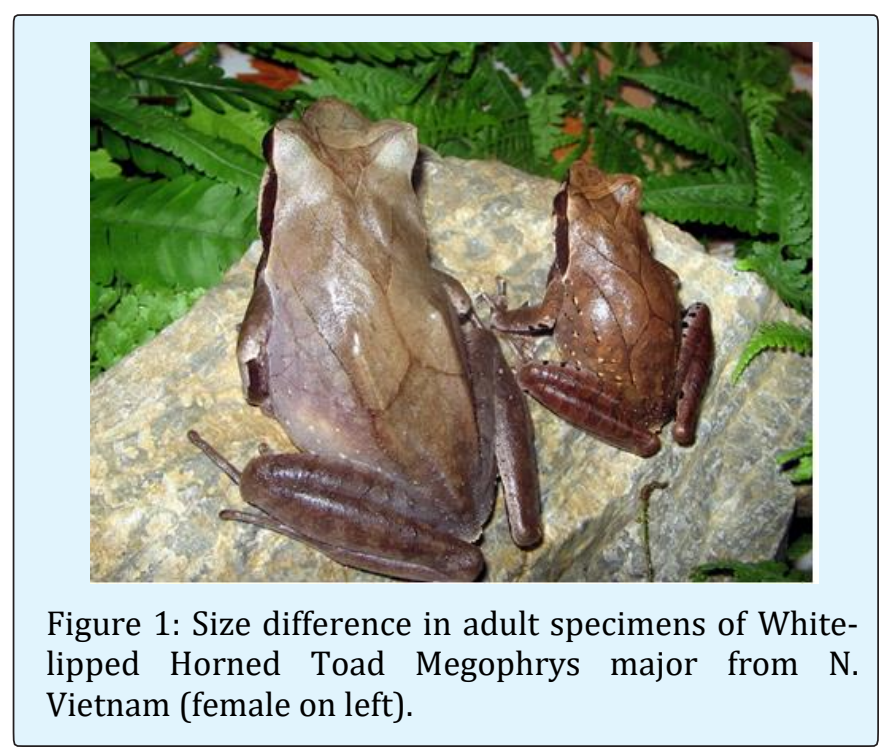




\section{International Journal of Zoology and Animal Biology}

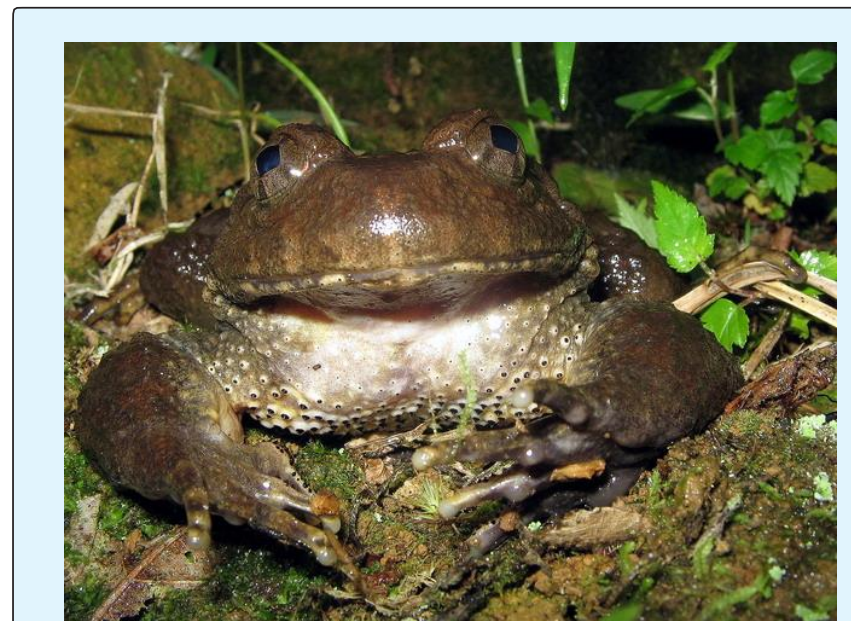

Figure 2: Large spines on front legs and chest of male of large bodied frog species Quasipaa boulengeri.

Size: in most frog species, mature females reach larger sizes than males (see Figures. 1, 3, 10). Both sexes of the same species develop their sizes to optimize their fitness. It is the reason for diverging body sizes, or even in a difference in male and females shapes [2,3]. Females grow larger than males in most species (61\% of urodeles, $90 \%$ of anurans), but males are often larger than females in species in which males engage in physical combat with each other [4]. But there is also some variability within this difference. For example, species inhabiting high montane areas may be much smaller in size than the same species from populations at lowlands [5]. etc;

Habitus (body shape): females as a rule are more robust and "swelled" because of growing and maturation in amphibian oocytes during oogenesis (See Figure 4); also, males in many species of toads have longer and more robust legs than females due to the need to hold larger females in amplexus during egg clutching.

Development of vocal sacs, nuptial pads, spines and tusks of male anurans appear to be adaptations to male combat and current species mating strategy, or theoretically even both (pers. obs. by M.F.). Interesting examples of the latter one are the spines possessed by adult males of Asiatic dicroglossid frogs of genus Quasipaa (see Figure 2). These large to very large sized terrestrial species exceeding $10 \mathrm{~cm}$ in length are able to cause a very serious injury even to humans (issue of blood) as the power of the clinch of their male clasp is very strong.

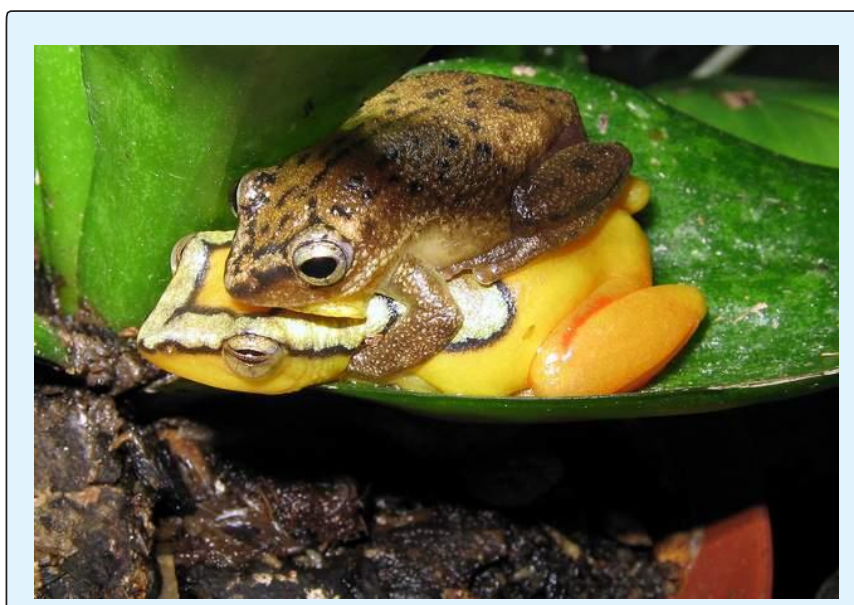

Figure 3: Sexual dichromatism in African spotted reed frog Hyperolius puncticulatus Male atop.

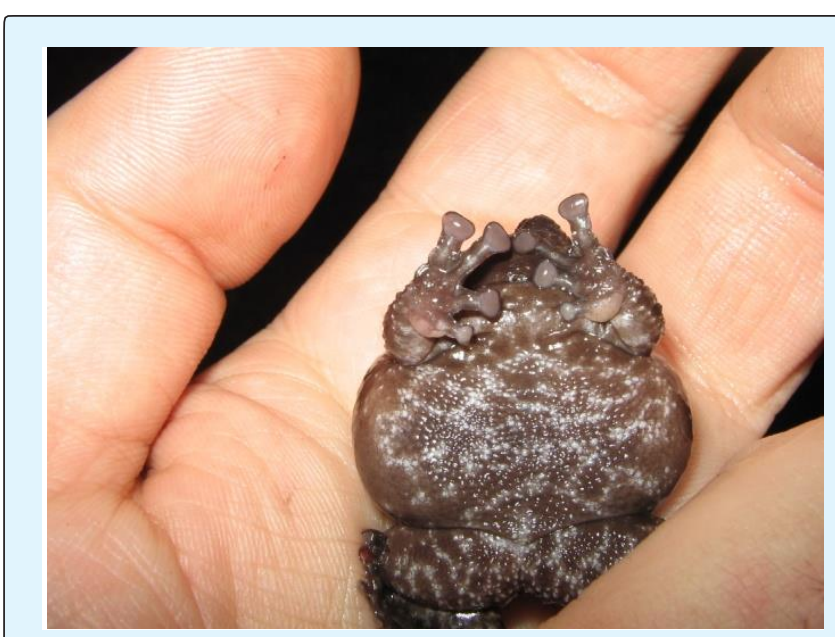

Figure 4: Habitually "swelled" female of Vietnam Bug Eyed frog Theloderma vietnamense showing dorsal full of developed eggs.

\section{Color, Called Sexual Dichromatism-the} Difference in Colour in Males and Females: This can be dynamic (temporary colour change in males) or even ontogenetic (permanent colour change in males or females (See Figure 3) [6]. Besides morphological characteristics, there are a number of behavioral characteristics that may additionally be used to distinguish males from females such as different types of vocalizing: breeding call and releasing call in males, etc. Here in, an addition sexual morphological characteristic which presents during the breeding period in males of some of the Asiatic Rhacophorid tree frog species (Anura: Rhacophoridae) is described, illustrated and discussed. 


\section{International Journal of Zoology and Animal Biology}

\section{Material and Methods}

All ex-situ observations were made by both authors on amphibian collection during their work at special department and facilities they're created in state zoo of the city of St. Petersburg ("Leningrad zoo"), Russia (Department of Amphibians and Invertebrates: 20082013). Collection contains over 100 species of caudated, anuran and legless (caecilians) amphibians from old and New World faunas.

Except different frogs from American and African continent (Hyperolius spp., Mantella spp., Boophis spp, Heterixalus spp., Scaphiophryne spp., Trachycephalus spp., Agalychnis spp., Hyla spp., Hypsiboas spp., Gastrotheca riobambae, various Dentrobatidae etc., a number of rhacophorid frog species have been bred there including most of Theloderma spp. known in captivity, many Rhacophorus spp., Polypedates spp., Kurixalus verrucosus etc [7]. Various other species (rhacophorids and others) didn't breed, but were kept at the same facility and also regularly entered breeding mood.

Breeding mood was detected and recognized on a signs of male changing behavior and/or development of vocal sac/ vocalization, amplexus observation, eggs deposition and/or found of tadpoles. Specimens were kept different ways: in groups of males and females, groups of males, as well as single males. Observations made on all groups.

\section{Main Context}

A great collection of different amphibians was established and kept during the existence of the Department of Amphibians and Invertebrates at Leningrad zoo.

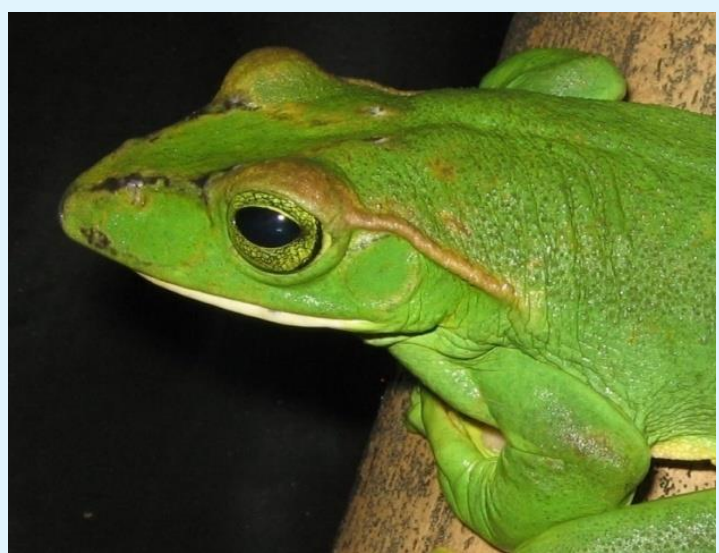

Figure 5: Male Rhacophorus feae with prominent beaklike projection during the breeding period.

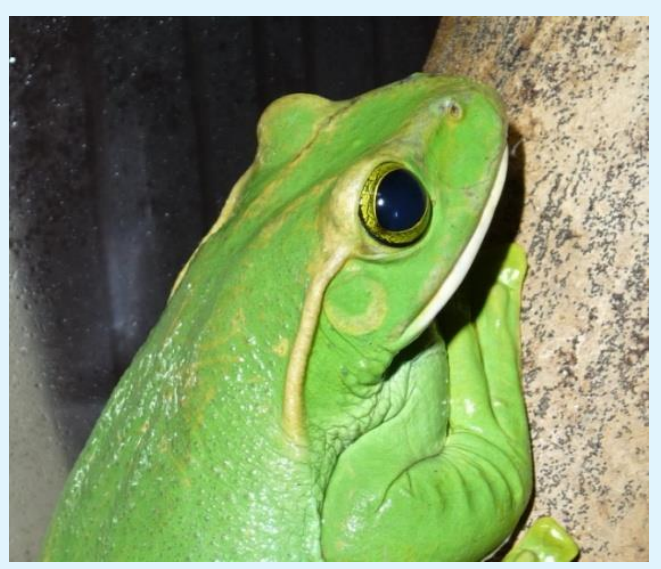

Figure 6: Same specimen of male Rhacophorus feae outside breeding period showing no beak-like projection.

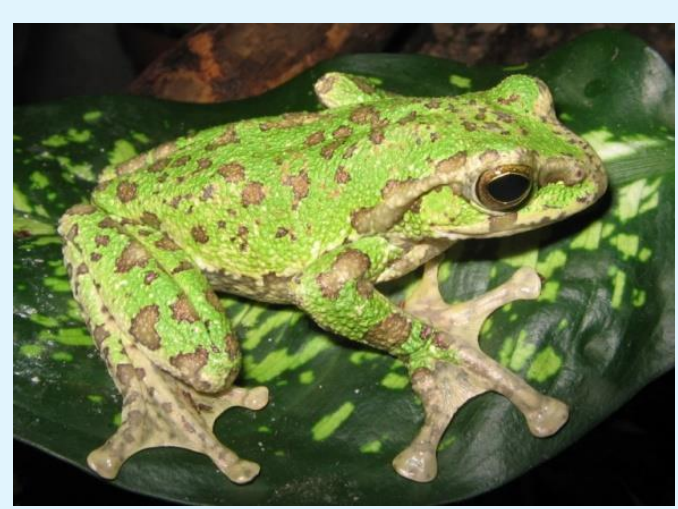

Figure 7: Male Rhacophorus duboisi with not developed beak-like projection outside of the breeding period.

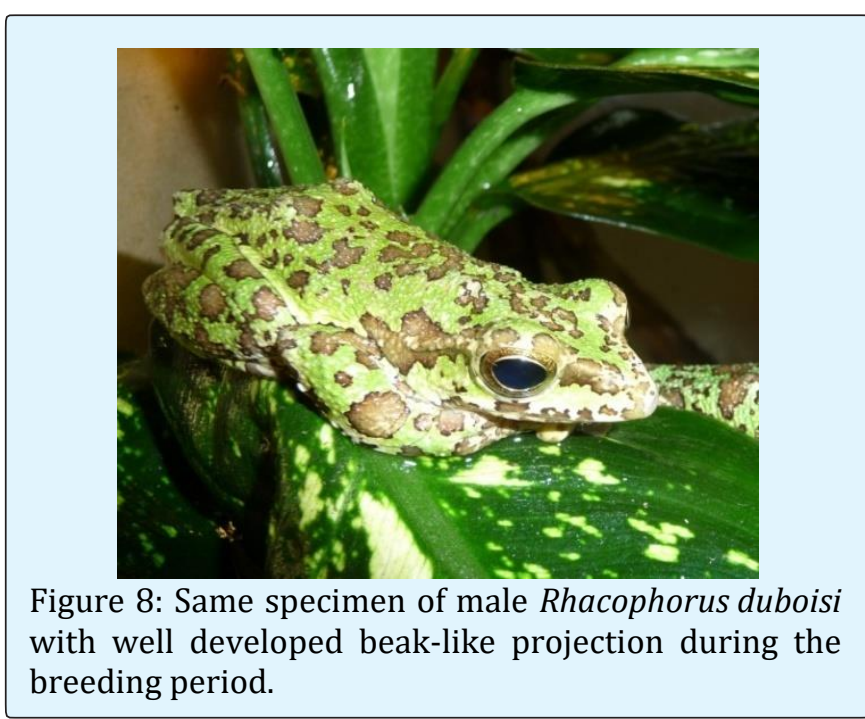




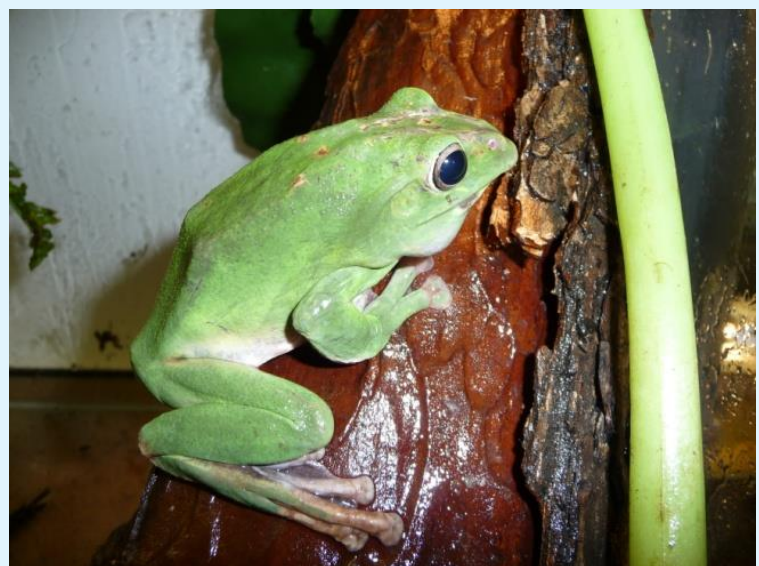

Figure 9: Large adult male of Rhacophorus dennysii with very evident beak-like projection during the breeding period, in vocalizing process.

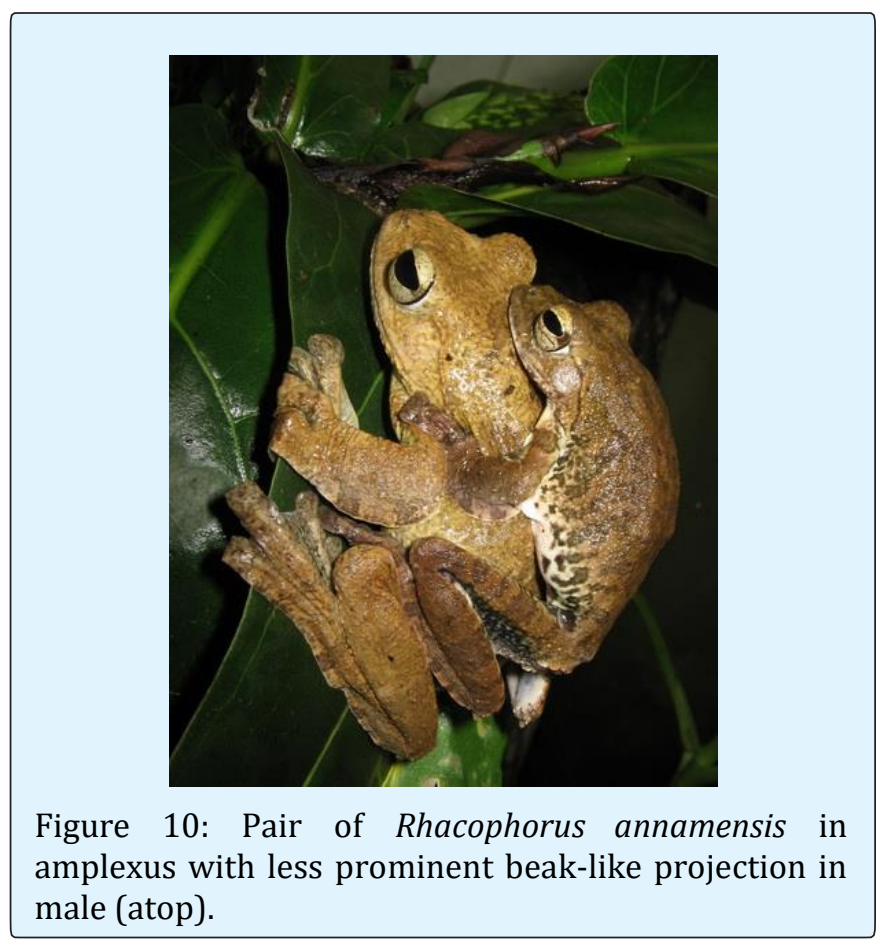

The collection focused on the development of conservation breeding of Asiatic amphibian fauna programs. While maintain the collection for years it was noted that males of several tree frog species kept in the zoo facility developed the more or less visible beak-like projections between the nostril opening on the anterior tip of the head (herein after referred to as "beak-like projection").
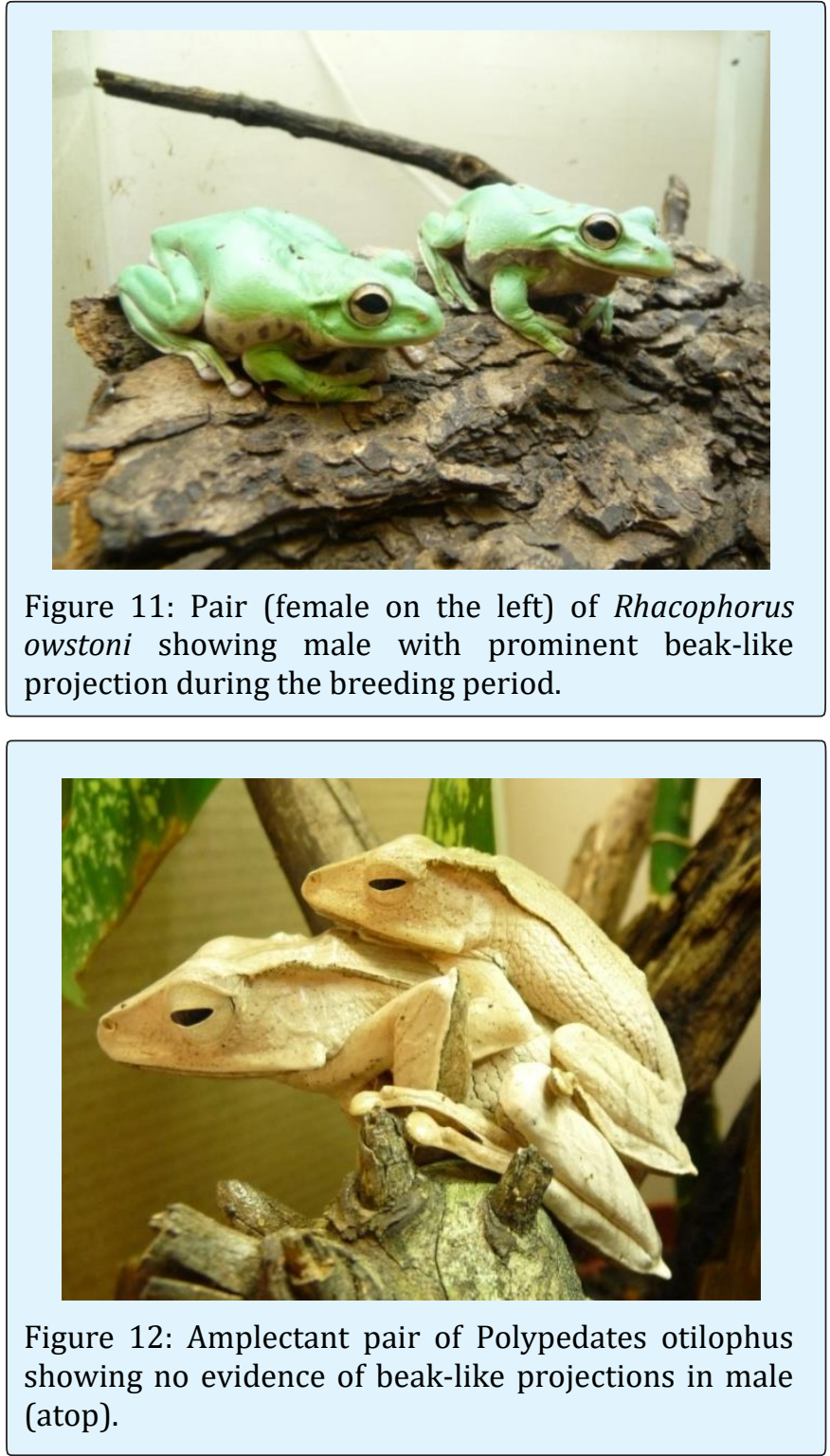

This character is clearly visible and illustrated herein in Rhacophorus feae showing same specimen of a male before entering the breeding season [6]. With rounded anterior tip of the head area (Figure 6), and during the period of breeding with developed beak-like projection at same area between nostrils opening (Figure 5) and Rhacophorus duboisi (see comparison of Figure 7 and Figure 8).

These species also include: Rhacophorus kio, Rhacophorus annamensis (Figure 10), Rhacophorus dennysii (Figure 9) and Rhacophorus owstoni (Figure 11). 


\section{International Journal of Zoology and Animal Biology}

Surveying the Internet (images) one can also find the same characteristic in rhacophorid males in other species like Rhacophorus malabaricus, Rhacophorus pseudomalabaricus, Rhacophorus maximus, Rhacophorus georgii, Rhacophorus dulitensis and some others.

\section{Discussion}

During the in-situ excursions in Vietnam (spring 2009: April-May - the beginning of the breading season for both caudata and anurans in North Vietnam, Cao Bang Province) the same characteristic was also noted by one of the excursion authors (M.F.) in the wild frogs of species Rhacophorus kio. This is also may confirm that development and possession of such a projection is evidently linked to the beginning of the reproductive season and present only in arboreal rhacophorid Asiatic frogs of the bigger sizes and never noted in any other frogs of World' fauna, including closely related genera of rhacophorid frogs of smaller sizes like Kurixalus.

Interestingly, having at that period nearly all presented in hobby species of Theloderma Tschudi, 1838, for a very long time, the beak-like projections was never observed for any of the species nor in some of the smaller species of their "beaked" congeners like Rhacophorus orlovi or even in some of the greater sizes species like Rhacophorus nigropalmatus a very large sized Polypedates otilophus (Figure 12), species from"Rhacophorus reinwardti group", etc.

\section{Conclusion}

The natural reason for the appearance of such an additional morphological character in adult males is yet unknown, and the authors can't suggest any valid role that aforementioned characteristic serves during the frogs' mating season. However, knowledge of this special character may help one to recognize the sexes of specimens of rhacophorid frogs for many useful purposes, such as maintaining conservation programs, captive breeding, collecting species/specimen data and observation for both amphibian hobbyists and field herpetologists. It is also shall be noted that this character is developed independently in current species in which this character is present: it doesn't matter if current specimen of such species involved into the breeding process or not taking part in breeding.
This character is suggested for inclusion into a matrix of different applications for constructing phylogeny of rhacophorid frogs, as well as usage as a one of taxonomical tool. The authors would like to thank their colleagues who assisted in their job during the period of work in the city zoo of St. Petersburg, Russia, also colleagues of Herpetology Division of Zoological Institute of RAS, St. Petersburg, Russia and Garrick Odell (USA) and anonymous reviewer for their corrections and suggestions of English manuscript.

\section{References}

1. Shine R (1989) Ecological causes for the evolution of sexual dimorphism: a review of the evidence. The Quarterly Review of Biology 64(4): 419-461.

2. Fairbairn DJ (2007) Introduction: The enigma of sexual size dimorphism. In: Fairbairn DJ, Blanckenhorn WU \& Szekely T (Eds.), Sex, size and gender roles. Evolutionary studies of sexual size dimorphism. Oxford University Press, Oxford.

3. Reinhard S, Kupfer A (2013) Evolution of the sexual dimorphism and the life strategies of the Salamandridae [Evolution des Sexualdimorphismus und der Lebensstrategien der Salamandridae]. Amphibia 12: 18-26.

4. Shine R (1979) Sexual Selection and Sexual Dimorphism in the Amphibia. Copeia 1979(2): 297306.

5. Feng X, Chen W, Junhua HU, JIANG J (2015) Variation and Sexual Dimorphism of Body Size in the Plateau Brown Frog along an Altitudinal Gradient. Asian Herpetological Research 6(4): 291-297.

6. Bell RC, Zamudio KR (2012) Sexual dichromatism in frogs: natural selection, sexual selection and unexpected diversity. Proc Biol Sci 279(1748): 46874693.

7. Bagaturova AA, Bagaturov MF (2012) First breeding of Fei's treefrog Rhacophorus feae in Leningrad Zoo [Erstnachzucht von Feas Riesenruderfrosch, Rhacophorus feae, im Leningrad Zoo.] Terraria 35, Reptiliensuche, Mai/Juni. 